\title{
Synthetic Pyrethroid Resistance in Field Strains of Helicoverpa armigera (Hubner) (Lepidoptera: Noctuidae) in Tamil Nadu, South India
}

\author{
P. Duraimurugan and A. Regupathy \\ Department of Agricultural Entomology, \\ Tamil Nadu Agricultural University, Coimbatore-641 003, India
}

\begin{abstract}
Resistance to synthetic pyrethroids was diagnosed in the field population of American bollworm, Helicoverpa armigera (Hubner) from Coimbatore, Tamil Nadu, South India during 20032004 cropping seasons. A Discriminating Dose (DD) bioassay technique was used to monitor fortnightly changes in resistance at Coimbatore where number of crops served as host plants for this pest. The resistance level of various synthetic pyrethroids to DDs varied from 80.0 to $96.4 \%$. The extent of resistance in terms of percent survival was 88.1-96.4, 87.2-94.3, 87.0-94.0, 84.3-94.2 and $80.0-91.8 \%$ for cypermethrin, fenvalerate, deltamethrin, lambda-cyhalothrin and beta-cyfluthrin, respectively.
\end{abstract}

Key words: Insecticide resistance, Helicoverpa armigera, Coimbatore, Tamil Nadu, South India

\section{INTRODUCTION}

The American bollworm Helicoverpa armigera (Hubner) (Lepidoptera: Noctuidae), an important polyphagous pest, is widely distributed in Europe, Africa, Asia and South Pacific regions ${ }^{[1]}$. It has a wide host range of over 360 plant species including the crop plants namely cotton, maize, sorghum, sunflower, tomato, okra and legumes ${ }^{[2]}$. Annual yield losses attributable to this pest in India alone over 1000 crores. In Tamil Nadu, the pest is found very wide spread in summer cotton tract often reaching high populations and during 'Rabi', the insect is found in serious proportions in cotton as well as on pigeon pea, chickpea, groundnut, sunflower, bhendi etc. causing extensive damage. Owing to the favorable environment and farming conditions like crop mosaic resulted in extensive and frequent use of pesticides ${ }^{[3]}$. The pyrethroids, which were considered most potent insecticides for its control, lost their efficacy ${ }^{[4,5]}$. Earlier reports indicated that cypermethrin and fenvalerate effectively reduced $H$. armigera population and damage ${ }^{[6-10]}$. Continuous use of pesticides against this pest resulted in the development of resistance to these pesticides. The first report of pyrethroid resistance in $H$. armigera reported from Australia in $1983^{[11]}$ was followed by reports from other countries viz., Turkey in 1984, Thailand and Columbia in 1984-85 $5^{[12]}$ and India in Andra Pradesh ${ }^{[13]}$, Tamil Nadu ${ }^{[14]}$, Delhi, Punjab and Haryana $^{[15]}$. The present investigations hence were conducted with a view to monitor the insecticide resistance in $H$. armigera to the generally used synthetic pyrethroids at Insecticide Resistance Management Laboratory of Department of Agricultural Entomology, Tamil Nadu Agricultural University
(TNAU), Coimbatore, Tamil Nadu during the 20032004 crop season which could be of use for formulating sound Insecticide Resistance Management (IRM) strategies.

\section{MATERIALS AND METHODS}

Insecticides and dilutions: The insecticide resistance monitoring bioassay was conducted with the most commonly used synthetic pyrethroids i.e., cypermethrin, fenvalerate, deltamethrin, lambdacyhalothrin and beta-cyfluthrin. The insecticide dilutions required for the Discriminating Dose (DD) assays were prepared from technical grade insecticides of known purity diluted with analytical grade acetone. The following DDs were used for resistance monitoring:

\begin{tabular}{lll}
\hline Chemical & $\mathrm{DD}\left(\mu \mathrm{g} \mu \mathrm{L}^{-1}\right)$ & Reference \\
\hline Cypermethrin & 0.1 & $\begin{array}{l}\mathrm{LD}_{99} \text { calibrated for NRI } \\
\text { pyrethroid susceptible strain } \\
\text { and for Australian susceptible } \\
\text { strain in early 1980's } \mathrm{s}^{[11]} .\end{array}$ \\
Fenvalerate & 0.2 & $\begin{array}{l}\mathrm{LD}_{99} \text { calibrated for susceptible } \\
\text { strain in Australia }\end{array}$ \\
Deltamethrin & 0.0125 & $\begin{array}{l}\mathrm{LD}_{99} \text { calibrated for susceptible } \\
\text { strain in Australia }\end{array}$ \\
Lambda-cyhalothrin & 0.025 & $\begin{array}{l}\mathrm{LD}_{99} \text { calibrated for susceptible } \\
\text { strain in Australia } \\
\mathrm{LD}_{99} \text { calibrated for susceptible } \\
\text { strain in Australia }\end{array}$ \\
Beta-cyfluthrin & 0.2 & \\
\hline
\end{tabular}

Insect and bioassay: The resistance level in $H$. armigera to different synthetic pyrethroids was monitored using discriminating dose screen by topical application of the insecticides. $H$. armigera populations of TNAU farm, Coimbatore District, Tamil Nadu were

Corresponding Author: Dr. P. Duraimurugan, Department of Agricultural Entomology, Tamil Nadu Agricultural University, Coimbatore - 641 003, India 
monitored for insecticide resistance to synthetic pyrethroids at fortnightly intervals for a period of one year (May 2003-April 2004). Third to fourth instar $H$. armigera larvae (30-40 mg) were culled out from field collection and placed individually on semi-synthetic diet in 12-well trays. One $\mu$ l aliquot of DDs was placed on the thoracic dorsum of each larva using a $1 \mu \mathrm{L}$ repeats dispenser (PB 600-01, Hamilton Co. Ltd.) fitted with a $50 \mu \mathrm{L}$ syringe and "Rheodyne needle". Control larvae were treated with acetone alone. For each treatment not less than 50 larvae were used. The observation on the mortality was made daily up to 144 $\mathrm{h}$ (6 days) after dosing. A larva is considered dead if it is unable to move in a co-ordinated manner when prodded. The total number of larvae dosed and total mortality was computed. The per cent survival/per cent resistance was calculated by using following formula ${ }^{[18]}$ :

\section{Percentt survival (or)}

Per cent resistance $=\frac{1-\text { No. of dead larvae }}{\text { No. of larvae dosed }} \times 100$

Also, the pooled binomial standard error was calculated using the formula:

$P \sqrt{\frac{(100-P)}{n-1}}$

Where:

$\mathrm{P}=$ Percentage of larvae surviving discriminating dose $\mathrm{n}=$ Total number of larvae tested that fortnight

\section{RESULTS AND DISCUSSION}

The resistance frequencies exhibited by $H$. The armigera population of Coimbatore for different synthetic pyrethroids viz., cypermethrin, fenvalerate, deltamethrin, lambda-cyhalothrin and beta-cyfluthrin were in the range of 80.4 to $98.3 \%$ (Table 1). No variation in resistance due to seasonal changes was observed for the five synthetic pyrethroid compounds tested. The difference among the individual compounds was not much throughout the period of monitoring. Irrespective of the hosts, $H$. armigera larvae showed a higher level of resistance to all the synthetic pyrethroids and the order of resistance was cypermethrin $>$ fenvalerate > deltamethrin > lambdacyhalothrin $>$ beta-cyfluthrin. The extent of resistance in terms of percent survival ranged from 88.1 to $96.4 \%$ for cypermethrin, 87.2 to $94.3 \%$ for fenvalerate, 87.0 to $94.0 \%$ for deltamethrin, 84.3 to $94.2 \%$ for lambda-cyhalothrin and 80.0 to $91.8 \%$ for beta-cyfluthrin.

Survey on resistance monitoring conducted during the present investigation revealed that the field population of $H$. armigera from Coimbatore, Tamil Nadu showed a very high level of resistance to synthetic pyrethroids (Table 1). The resistance levels observed confirmed the high level of resistance to cypermethrin and fenvalerate reported earlier through monitoring studies conducted since 1993 by Gowthaman $^{[19]}$, Pasupathy and Regupathy ${ }^{[14]}$, Regupathy ${ }^{[20]}$ and Regupathy et $a .^{[3,21,22]}$.

Table 1: Resistance frequency (RF) to synthetic pyrethroids in Coimbatore population of H. armigera during 2003-2004

\begin{tabular}{|c|c|c|c|c|c|c|c|c|c|c|}
\hline \multirow[t]{2}{*}{ Months } & \multicolumn{2}{|c|}{ Cypermethrin } & \multicolumn{2}{|c|}{ Fenvalerate } & \multicolumn{2}{|c|}{ Deltamethrin } & \multicolumn{2}{|c|}{ Lambdacyhalothrin } & \multicolumn{2}{|c|}{ Betacyfluthrin } \\
\hline & RF & SE & RF & SE & RF & SE & RF & SE & RF & SE \\
\hline 1-15 May'03 & 95.4 & 2.6 & 94.2 & 2.8 & 87.0 & 5.0 & 90.8 & 3.6 & 83.3 & 5.1 \\
\hline 16-31 May '03 & 94.8 & 2.9 & 94.3 & 2.8 & 91.8 & 4.0 & 89.5 & 4.1 & 84.3 & 5.1 \\
\hline 1-15 June '03 & 96.4 & 2.5 & 93.3 & 3.2 & 88.9 & 4.3 & 88.0 & 4.6 & 84.9 & 5.0 \\
\hline 16-30 June'03 & NT & NT & NT & NT & NT & NT & NT & NT & NT & NT \\
\hline 1-15 July'03 & NT & NT & NT & NT & NT & NT & NT & NT & NT & NT \\
\hline 16-31 July '03 & 96.1 & 2.7 & 90.2 & 4.2 & 87.8 & 4.7 & 88.5 & 4.1 & 88.1 & 5.1 \\
\hline 1-15 Aug. '03 & 94.5 & 3.1 & 88.9 & 4.3 & 89.5 & 4.1 & 87.5 & 4.2 & 85.9 & 4.4 \\
\hline 16-31 Aug. '03 & 93.0 & 3.4 & 92.4 & 3.3 & 90.6 & 3.7 & 84.3 & 5.1 & 84.2 & 4.9 \\
\hline 1-15 Sept. '03 & 93.8 & 3.0 & 90.0 & 4.3 & 90.7 & 4.0 & 87.2 & 4.9 & 80.0 & 5.2 \\
\hline 16-30 Sept. '03 & 89.8 & 4.0 & 92.7 & 3.5 & 90.8 & 3.6 & 89.6 & 3.8 & 86.5 & 4.8 \\
\hline 1-15 Oct. '03 & 90.2 & 4.2 & 92.2 & 3.4 & 92.5 & 3.2 & 88.2 & 5.6 & 83.3 & 5.8 \\
\hline 16-31 Oct. '03 & 96.4 & 2.5 & 93.4 & 3.2 & 93.3 & 3.2 & 90.2 & 4.2 & 89.8 & 4.4 \\
\hline 1-15Nov. '03 & 89.2 & 5.2 & 91.5 & 3.7 & 91.7 & 3.6 & 93.5 & 3.7 & 91.8 & 3.5 \\
\hline 16-30 Nov. '03 & 89.6 & 3.8 & 93.2 & 3.3 & 89.1 & 3.9 & 90.6 & 3.7 & 88.2 & 4.6 \\
\hline 1-15 Dec. '03 & 92.1 & 3.4 & 90.0 & 4.3 & 94.0 & 3.4 & 90.2 & 4.2 & 89.5 & 4.1 \\
\hline 16-31 Dec. '03 & 93.4 & 3.2 & 90.4 & 4.1 & 91.8 & 3.5 & 89.7 & 4.0 & 86.0 & 5.3 \\
\hline 1-15 Jan.'04 & 92.2 & 3.8 & 91.8 & 4.0 & 91.5 & 3.7 & 90.2 & 4.2 & 87.8 & 5.2 \\
\hline 16-31 Jan. '04 & 94.4 & 3.1 & 92.0 & 3.9 & 93.0 & 3.9 & 91.1 & 3.8 & 88.1 & 5.1 \\
\hline 1-15 Feb. '04 & 88.5 & 4.1 & 92.5 & 3.7 & 89.8 & 4.0 & 90.6 & 3.7 & 89.3 & 4.2 \\
\hline 16-29 Feb. '04 & 88.1 & 5.1 & 87.2 & 4.9 & 93.0 & 3.4 & 93.3 & 3.2 & 90.2 & 4.2 \\
\hline 1-15 March'04 & 90.2 & 4.2 & 90.0 & 4.3 & 91.5 & 3.7 & 92.9 & 3.5 & 87.2 & 4.9 \\
\hline 16-31 March'04 & 94.5 & 3.1 & 94.0 & 3.3 & 90.7 & 3.9 & 92.0 & 3.8 & 90.0 & 4.2 \\
\hline 1-15 April'04 & 95.3 & 3.1 & 93.3 & 3.2 & 91.1 & 4.2 & 93.7 & 3.5 & 88.5 & 4.4 \\
\hline 16-30 April '04 & 95.8 & 2.9 & 93.6 & 3.6 & 91.8 & 3.9 & 94.2 & 3.2 & 87.5 & 4.4 \\
\hline
\end{tabular}

SE- Pooled binomial standard error $( \pm)$ NT- Not tested 
Similarly Manikandan ${ }^{[23]}$ reported high level of resistance to fenvalerate and deltamethrin. Tamilselvi ${ }^{[24]}$, Niranjankumar ${ }^{[25]}$ and Ramasubramanian ${ }^{[26]}$ recently confirmed the high level of resistance to deltamethrin, cypermethrin, lambdacyhalothrin, fenvalerate and beta-cyfluthrin in Tamil Nadu. The resistance development due to exposure of earlier compounds was reported from different parts of India $^{[4,13,15,27-36]}$. Thus, resistance to the pyrethroids seems to be static without showing any decline. Obviously the availability of succession of the host crops (okra, tomato, pigeonpea, chickpea, sunflower, cotton) and intense insecticide applications is responsible for the further maintenance and spread of insecticide resistance in South India. The data presented indicate the need for continuous monitoring of insecticide resistance in $H$. armigera and for identifying the actual mechanisms of resistance involved and in the development of insecticide resistance management strategy.

\section{ACKNOWLEDGEMENT}

The financial support from the Common Fund for Commodities (CFC) Europe, International Cotton Advisory Committee (ICAC) U.S.A and Natural Resource Institute (NRI), U.K. is acknowledged.

\section{REFERENCES}

1. Reed, W. and C.S. Pawar, 1982. Heliothis: A global problem. In: Proc. Int. Workshop Heliothis management. ICRISAT, Patancheru, India. Pp: 9.

2. Singh, H. and G. Singh, 1975. Biological studies on Heliothis armigera (Hubner) in Punjab. Indian J. Ent., 37: 154-164.

3. Regupathy, A., D.S. Rajavel, S. Rajkumar and D. Russel, 1999. Present status of insecticide resistance in Helicoverpa armigera and its management in Tamil Nadu, India. In: Proc. ICAC -CCRI Regional Consultation Insecticide Resistance Management in Cotton, June 28- July 1, Multan, Pakistan.

4. Armes, N.J., D.R. Jadhav, G.S. Bond and A.B.S. King, 1992. Insecticide resistance in Helicoverpa armigera in South India. Pesticide Sci., 34: 355364.

5. Ahmad, M., M.I. Arif, Z. Ahmad and M.R. Attique, 1997. Pyrethroid resistance of Helicoverpa armigera (Lepidoptera: Noctuidae) in Pakistan. Bull. Ent. Res., 87: 343-347.

6. Venugopal, M.S., S. Pasupathy and S. Jagannathan, 1986. Efficacy of new synthetic pyrethroids in the control of cotton bollworm in India. Pestology, 10: 5-7.

7. Mustafee, T.P. and K.N. Reddy. 1989. Chemical control of cotton pests. Pestology, 13: 8-13.
8. Chandurwar, R.D. and N.R. Seeras. 1994. Efficacy of new insecticides against gram pod borer, Helicoverpa armigera (Hubner) on chick pea. Pestology, 18: 23-25.

9. Mirikar, A.V., M.N. Borle, P.S. Bonkar and J.E. Jahagirdar, 1995. Efficacy of pyrethroid urea mixture on cotton bollworms. Pestology, 19: 9-11.

10. Banerjee, S.K., K.S. Turkar and R. Ratan, 2000. Efficacy of newer insecticides against bollworms of cotton. Pestology, 24: 12-14.

11. Gunning, R.V., C.S. Easton, L.R. Greenup and V.E. Edge, 1984. Pyrethroid resistance in Heliothis armigera (Hubner) (Lepidoptera: Noctuidae) in Australia. J. Econ. Entomol., 77: 1283-1287.

12. Ahmad, M. and A.R. Mc Caffery, 1988. Resistance to insecticides in a Thailand strain of Heliothis armigera (Hubner) (Lepidoptera: Noctuidae). J. Econ. Entomol., 81: 45-48.

13. Armes, N.J., D.R. Jhadav and K.R. De Souza, 1996. A survey of insecticide resistance in Helicoverpa armigera in the Indian sub-continent. Bull. Ent. Res., 86: 499-514.

14. Pasupathy, S. and A. Regupathy, 1994. Status of insecticide resistance in the American bollworm, Helicoverpa armigera in Tamil Nadu. Pestic. Res. J., 6: 117-120.

15. Mehrotra, K.N. and A. Phokela, 1992. Pyrethroids of populations in Punjab in cotton. Pestic. Res. J., 4: 59-61.

16. Forrester, N.W. and M. Cahill, 1987. Management of insecticide resistance in Heliothis armigera (Hubner) in Australia. In: M.G. Forel, D.W. Holloman, B.P.S. Khambay and K.M. Sawicki (Eds.) Combating Resistance to Xenobiotics, Biological and Chemical Approaches, Ellis Hordwood Publishers, pp: 127-137.

17. Forrester, N.W., M. Cahill, L.J. Bird and J.K. Layland, 1993. Management of pyrethroid and endosulfan resistance in Helicoverpa armigera (Lepidoptera: Noctuidae) in Australia. Bull. Entomol. Res., 1:1-132.

18. Regupathy, A. and K.P. Dhamu, 2001. Statistics Workbook for Insecticide Toxicology. Softeck Computers, Coimbatore, pp: 206.

19. Gowthaman, S., 1994. Studies on monitoring techniques for detecting insecticide resistance in Helicoverpa armigera (Hubner). M.Sc. (Ag.) Thesis, Tamil Nadu Agricultural University, Coimbatore, India, pp: 55.

20. Regupathy, A., 1995. Problems and prospects of management of insecticide resistance in Helicoverpa armigera in India. In: Constable, G.A. and N.W. Forrester (Eds.) Challenging the Future: Proc. World Cotton Conference-I, 14-17 Feb., Brisbane, Australia, CSIRO, Melbourne, pp: 556562. 
21. Regupathy, A., K.R. Kranthi, G. Asokan, N.J. Armes, N.V. Rao, R.P. Soundararajan and D.A. Russell, 1997. Mechanisms of insecticide resistance in field populations of Helicoverpa armigera in India. In: Proc. Intl. Conf. on Integrated Approach to Combating Resistance, 1416, April, ICAR, Rothamsted, Harpenden, Herts, UK., pp: 117.

22. Regupathy, A., D. Jadhav, S.K. Kapoor, D. Singh, K. Kranthi and D. Russel, 1998. Patterns of insecticide cross resistance in Helicoverpa armigera and Bemisia tabaci in India. In: Newfrontiers in Cotton Research: World Cotton Res. Conf 2., 6-12 Sep., Athens, Greece. Abst., pp: 178.

23. Manikandan, P., 1998. Comparative resistance of Helicoverpa armigera populations to some insecticides in different places of Tamil Nadu. Insect Environ., 4: 9-10.

24. Tamilselvi, S., 2001. Studies on detoxification mechanism of pyrethroid resistance in Helicoverpa armigera (Hubner) populations of Tamil Nadu. M.Sc. (Ag.) Thesis, Tamil Nadu Agricultural University, Coimbatore, India, pp: 84.

25. Niranjankumar, B.V., 2002. Management of insecticide resistance in Helicoverpa armigera (Hubner): Laboratory measured resistance level and field control. PH. D. Thesis, Tamil Nadu Agricultural University, Coimbatore, India, pp: 212.

26. Ramasubramanian, T., 2003. Pattern of cross resistance in pyrethroid selected populations of Helicoverpa armigera (Hub.). Ph.D. Thesis, Tamil Nadu Agricultural University, Coimbatore, India.

27. Reddy, G.R., K.C. Chitra and P.K. Rao, 1991. Development of resistance to insecticides in different populations of Heliothis armigera (Hubner) (Noctuidae: Lepidoptera) in Andhra Pradesh. Indian J. Entomol., 53: 393-395.
28. Armes, N.J., S.K.Banerjee, K.R. De Souza, D.R Jadhav, A.B.S. King, K.R. Kranthi, A. Regupathy, T. Surilivelu and N. Venugopal Rao, 1994. Insecticide resistance in Helicoverpa armigera in India: Recent Developments. Brighton Crop Protection Conference-Pests and Diseases-1994. pp: 437-442.

29. Srivastava, C.P., 1995. Insecticide resistance is Helicoverpa armigera in India. Resist. Pest Mgmt., 7: 4-5.

30. Baruah, A.A.L.H. and R. Chauhan, 1996. Relative toxicity of three synthetic pyrethroids and endosulfan to susceptible strain of Helicoverpa armigera (Hubner) from Hissar (India). J. Ent. Res., 20: 89-91.

31. Kranthi, K.R., N.J. Armes, G.V. Rao, S. Raj and V.T. Sundaramoorthy, 1997. Seasonal dynamics of metabolic mechanisms mediating pyrethroid resistance in Helicoverpa armigera in Central India. Pestic. Sci., 50: 91-98.

32. Roasaiah, B., A.S. Reddy, V.N. Rao, P. Rajasekar and M. Venkataiah, 1997. Insecticide resistance in Helicoverpa armigera (Hubner) in Andhra Pradesh. Ind. J. Plant Prot., 25: 93-95.

33. Tripathy, M.K. and H.N. Singh, 1999. Monitoring of insecticide resistance in Heliothis armigera (Hubner) from areas receiving very low insecticidal applications at Varanasi, Uttar Pradesh. J. Entomol. Res., 23: 281-291.

34. Tikar, S.N., N.G.V. Rao, D.R. Arya and M.P. Moharll, 2001. Pyrethroid resistance monitoring and mechanisms in Helicoverpa armigera (Hubner) in Central India. Crop Res., 22: 474-478.

35. Chavan, V.M. and S.A. Nimbalkar, 2003. Seasonal monitoring of insecticide resistance in Helicoverpa armigera (Hubner). Indian J. Plant Prot., 31: 20-24.

36. Regupathy, A., K. Kranthi, J. Singh, A. Iqabal, Y. $\mathrm{Wu}$ and D.A. Russell, 2004. Patterns and magnitude of insecticide resistance levels in India, Pakistan and China. In: J.V. Biljon and D. Joubert (Eds.) Proc. World Cotton Conference III, 9-13, March, Cape Town, South Africa, pp: 1215-29. 